\title{
LOW COST AND PORTABLE ELECTRONIC SYSTEM BASED ON ELECTROCHEMICAL AND PM SENSORS FOR THE MEASUREMENT OF AIR QUALITY MONITORING
}

\author{
PATRICIA ARROYO ${ }^{1}$, FÉLIX MELÉNDEZ ${ }^{1}$, SERGIO RODRÍGUEZ1 ${ }^{1}$, JOSÉ IGNACIO SUÁREZ ${ }^{1}$, \\ EDUARDO PINILLA ${ }^{2}$, SERGIO MASA $^{3}$, ESTHER HONTAÑON $^{3} \&$ JESÚS LOZANO $^{1}$ \\ ${ }^{1}$ Escuela de Ingenierías Industriales, Universidad de Extremadura, Spain \\ ${ }^{2}$ Facultad de Ciencias, Universidad de Extremadura, Spain \\ ${ }^{3}$ Instituto de Tecnologías Físicas y de la Información, Consejo Superior de Investigaciones Científicas, Spain
}

\begin{abstract}
A portable, low-cost system for air quality measurement is presented in this communication. For the measurement of the main pollutants both gaseous $\left(\mathrm{NO}_{2}, \mathrm{NO}, \mathrm{O}_{3}, \mathrm{CO}\right)$ and solid $\left(\mathrm{PM}_{10}\right.$ and $\left.\mathrm{PM}_{2.5}\right)$, electrochemical and particulate matter (PM) sensors are used, all from Alphasense. The device also features measurement of meteorological data such as temperature and humidity. In addition, different communication modules (Bluetooth and ethernet among others) and storage of acquired data are included. The control core of the system is a low power microcontroller from the manufacturer ST (STM32L476), and the whole device is powered through a 230V AC socket. Air sampling is done actively, and therefore the equipment includes a pump. The complete system has been tested in real conditions during two months next to the fixed reference station located in Badajoz, Spain. Its general operation has been successful, with strong correlation results, although the calibration of the electrochemical sensors should be modified in future work to improve its performance, especially in environments with low concentrations of pollution.
\end{abstract}

Keywords: air quality, electrochemical sensors, particulate matter, low-cost, monitoring.

\section{INTRODUCTION}

Atmospheric pollutants are currently a major focus of attention worldwide due to the great damage they cause. For this reason, it is of great importance to have monitoring that provides data on the subject. For this purpose, traditional reference stations are used. However, due to its high cost and large size, problems of spatial-temporal resolution arise. Namely, the stations include expensive air quality sensors, which provide accurate data but only at a few predefined locations. As a partial solution to this problem, a low-cost device generation is becoming increasingly important [1]. These devices are not intended to replace reference instruments, especially for application purposes, but rather to be a complementary source of information on air quality [2].

The main components of these low-cost systems are certainly the gas sensors. These sensors must be low cost, for which there are different technologies: mainly including resistive sensors, electrochemical sensors, nondispersive infrared (NDIR) detectors, absorption sensors, and photoionization detectors (PIDs) [3]. Although they are not the smallest or the cheapest, electrochemical sensors seem to be the best option for the detection and quantification of air pollutants, as they are selective sensors (with low cross sensitivity). That is why they have been selected for the work presented, since the system does not intend to be personal or only for detection, but portable, for quantification and with the highest possible reliability. In particular, the Alphasense's A4 model has been selected, mounted on the Analogue Front End interface supplied by the manufacturer. Nowadays, these sensors are the most commonly used for this purpose, and have been tested by numerous authors and in different situations [4]-[8]. 
The presented device for air quality monitoring is outlined in different sections in this paper. First, the electronic design and composition of the system is described, then the main results obtained in correlation with the reference station are presented, and finally the main conclusions are briefly detailed.

\section{MATERIALS AND METHODS}

This communication presents a prototype for stationary and mobile air quality monitoring. This device includes four electrochemical gas sensors to measure $\mathrm{CO}, \mathrm{NO}_{2}, \mathrm{NO}$ and $\mathrm{O} 3$ (main atmospheric pollutants), and a particle sensor to measure $\mathrm{PM}_{10}$ and $\mathrm{PM}_{2.5}$. The Analogue Front End supplied by Alphasense has been used for connecting the sensors to the system. An external 24-bit digital-analogue converter with 8 inputs is used to read the value of the sensors. On the other hand, the PM sensor used is the OPC-N3 model, also from Alphasense, which also provides humidity and temperature information. However, another humidity and temperature sensor has been integrated, as the previous one may not represent the actual environmental conditions. A picture of these sensors selected for the design, both gas and PM, is shown in Fig. 1.

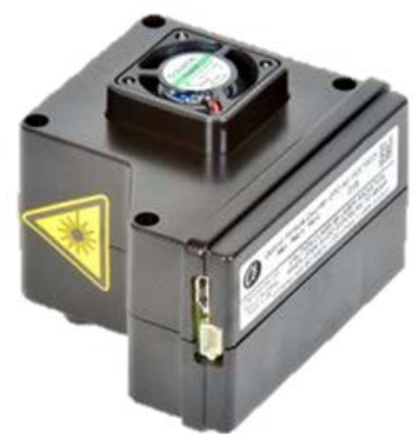

(a)

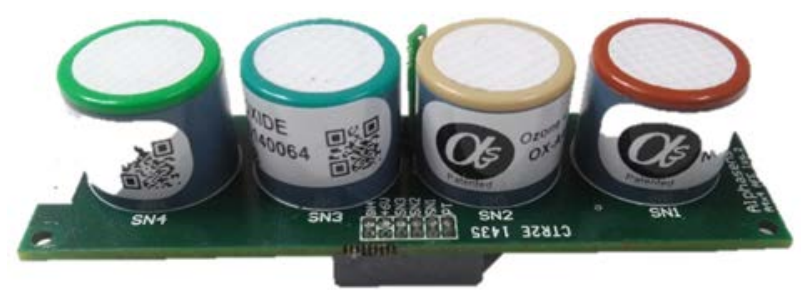

(b)

Figure 1: Gas and PM sensors (from Alphasense) used in the device design. (a) OPC-N3; and (b) AFE A4.

The power supply of the electronic part must be between 1.8 and $5.5 \mathrm{~V}$. This input voltage is converted into $5 \mathrm{~V}$ and $3.3 \mathrm{~V}$, which are the necessary voltages for the supply of the different components. The control of the system is based on the use of an STM32L476 Nucleo-Board, an ultra-low-power microcontroller based on a high-performance 32-bit core operating at a frequency of up to $80 \mathrm{MHz}$. On the other hand, it incorporates modules for Low Energy Bluetooth and Ethernet communication in order to receive data on smart mobile 
devices or data clouds. Moreover, these data from the sensors can also be stored on a microSD card attached to the prototype. Finally, the design includes the possibility of external connection of LoRA or GSM communication modules for wireless data transmission, and the power control function of an external fan. Fig. 2 shows the designed electronic prototype and points out some of its main elements. Otherwise, a block diagram of the electronic design of the system is shown in Fig. 3. The dimensions of the designed electronic printed circuit board are $90 \mathrm{~mm} \times 110 \mathrm{~mm}$.

In order to simplify the connection of the system in different locations, a $230 \mathrm{~V} \mathrm{AC}$ to $5 \mathrm{~V}$ converter and a mains plug have been included. Moreover, the system is equipped with an electric pump that allows the air to be conducted from the outside to the sensor cell. In this way, by maintaining a constant flow of the sample through the sensor cell, interference related to pressure changes will be reduced. This factor is very important in the use of electrochemical sensors. The sensor cell is made of metal in order to reduce the effects of electromagnetic noise. The entire system has been encapsulated in a watertight box for outdoor placement. A picture of the complete system, detailing the main components, is shown in Fig. 4.

\section{RESULTS}

The operation of the developed system has been successfully tested for two months (August and September 2019) in parallel with the fixed reference station of Badajoz, in Spain. A picture of the final system installation is displayed in Fig. 5. The data sampling period was 30 seconds, although it was subsequently averaged every 10 minutes for graphical representation and comparison with data from the reference station. Real-time data was stored in the microSD included in the system.

A temperature compensation has been performed on the signal from the gas sensors applying the algorithm recommended by the manufacturer. The temperature compensation factors are depicted in Table 1. Regarding humidity and pressure, neither compensation algorithm has been applied.

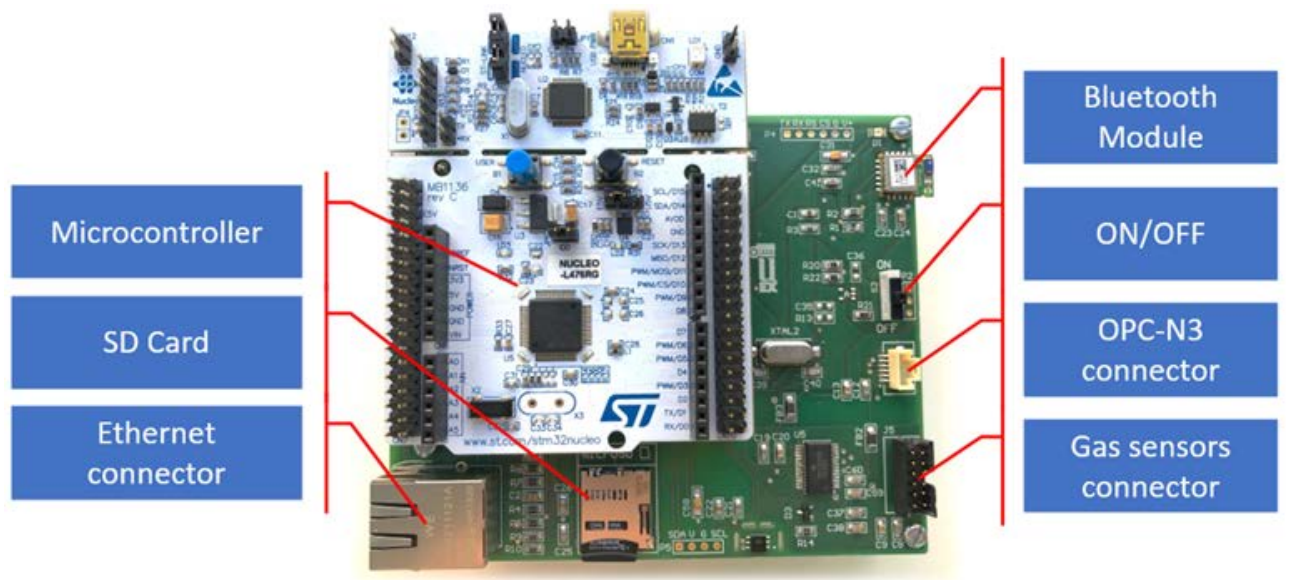

Figure 2: Electronic system designed. 


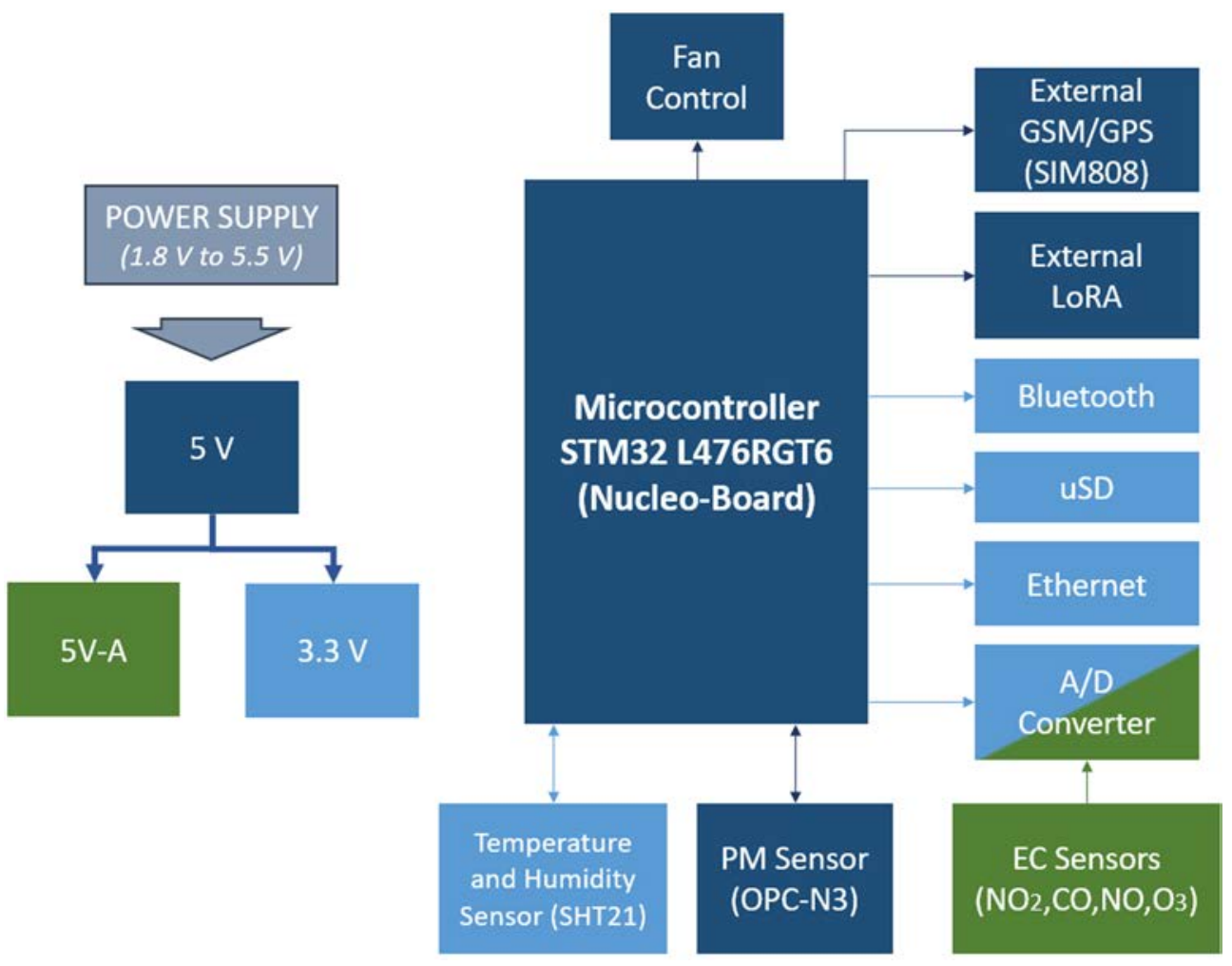

Figure 3: Block diagram of the electronic system.

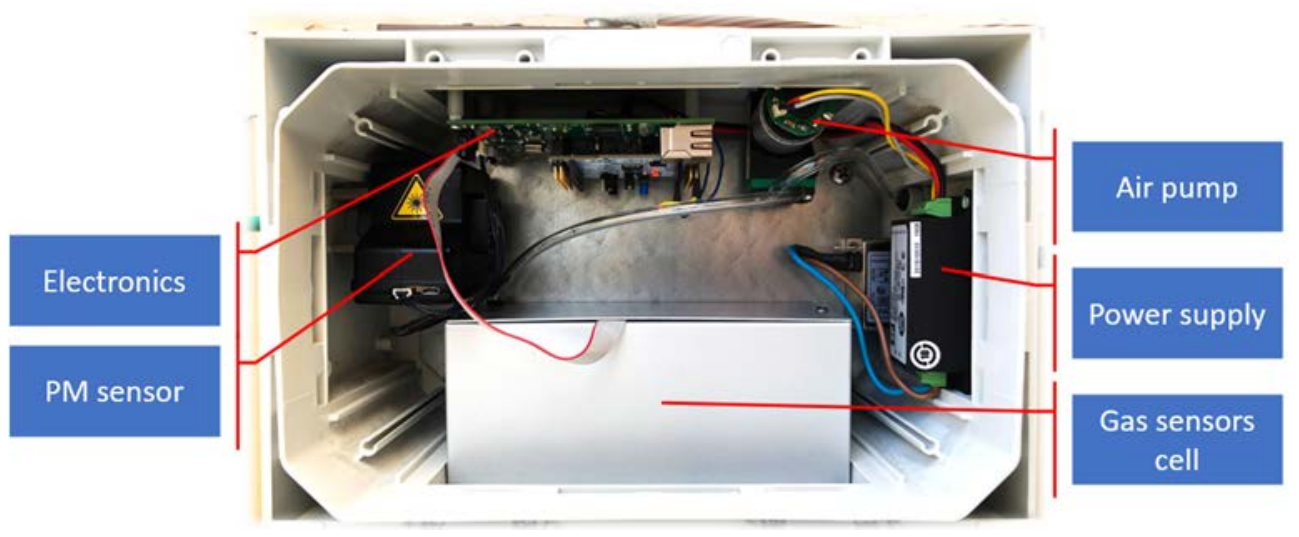

Figure 4: Complete system developed. 


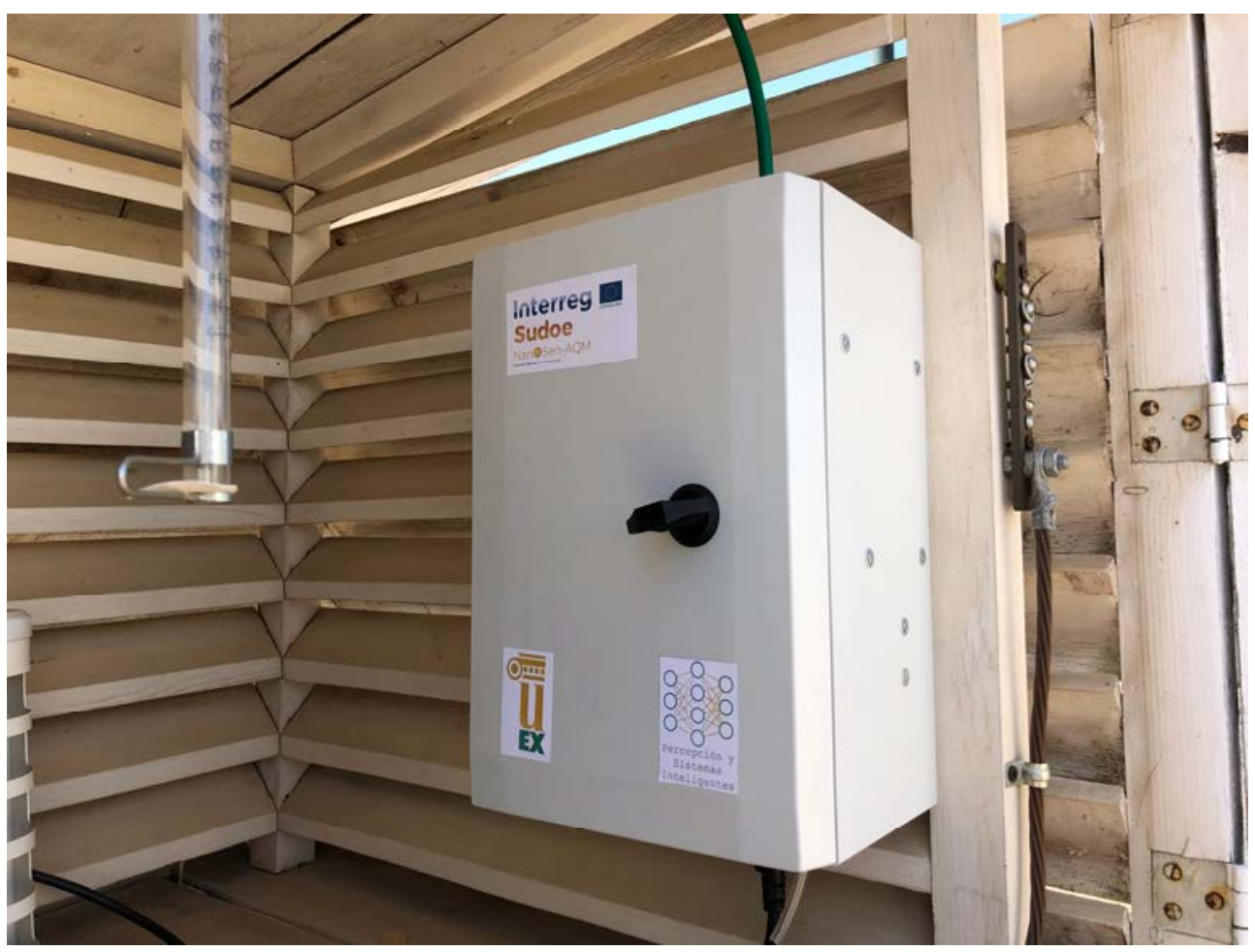

Figure 5: Air quality measurement system installed in parallel with the Badajoz reference station.

Table 1: Factor for temperature compensation recommended by manufacturer.

\begin{tabular}{|l|c|c|c|c|}
\hline & $\mathrm{T}^{\mathrm{a}} \leq 0$ & $0<\mathrm{T}^{\mathrm{a}} \leq 10$ & $10<\mathrm{T}^{\mathrm{a}} \leq 30$ & $\mathrm{~T}^{\mathrm{a}}>30$ \\
\hline $\mathrm{NO}_{2}$ & 1.09 & 1.09 & 1.33 & 3 \\
\hline $\mathrm{O}_{3}$ & 0.75 & 1.28 & 1.28 & 1.28 \\
\hline $\mathrm{NO}$ & 1.48 & 1.48 & 2.02 & 1.72 \\
\hline $\mathrm{CO}$ & 1 & 1 & -1 & -0.76 \\
\hline
\end{tabular}

\subsection{Temperature and relative humidity results}

Firstly, as proof that the electronic system is working properly, a comparison was made between the temperature and humidity data of the reference station and the developed prototype. The comparison graphs can be seen in Fig. 6, where the blue line represents the value recorded by the reference station, and the orange line represents the value measured by the prototype system. It can be observed that the correlation is quite accurate, from which it can be concluded that the electronic system is working correctly and, the errors that may appear, would be due to the sensors, their calibration, or the post-processing stage. 


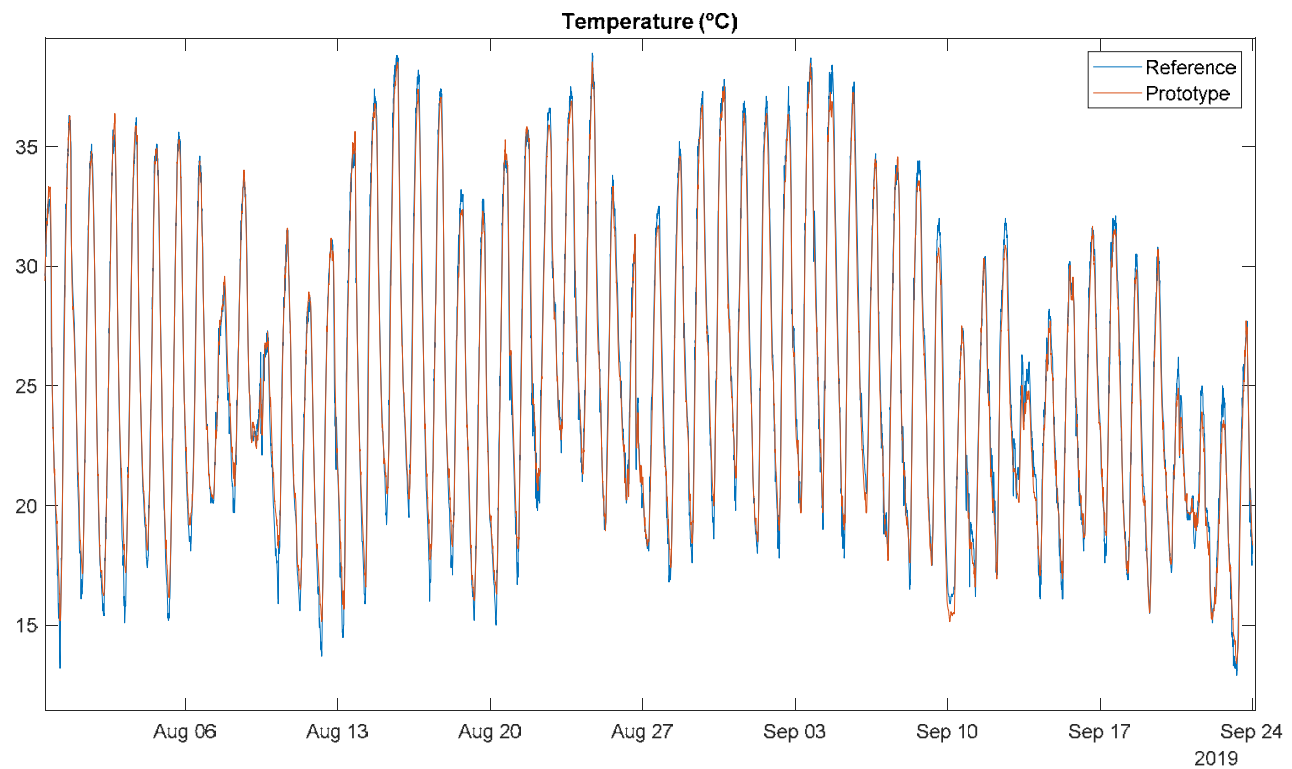

(a)

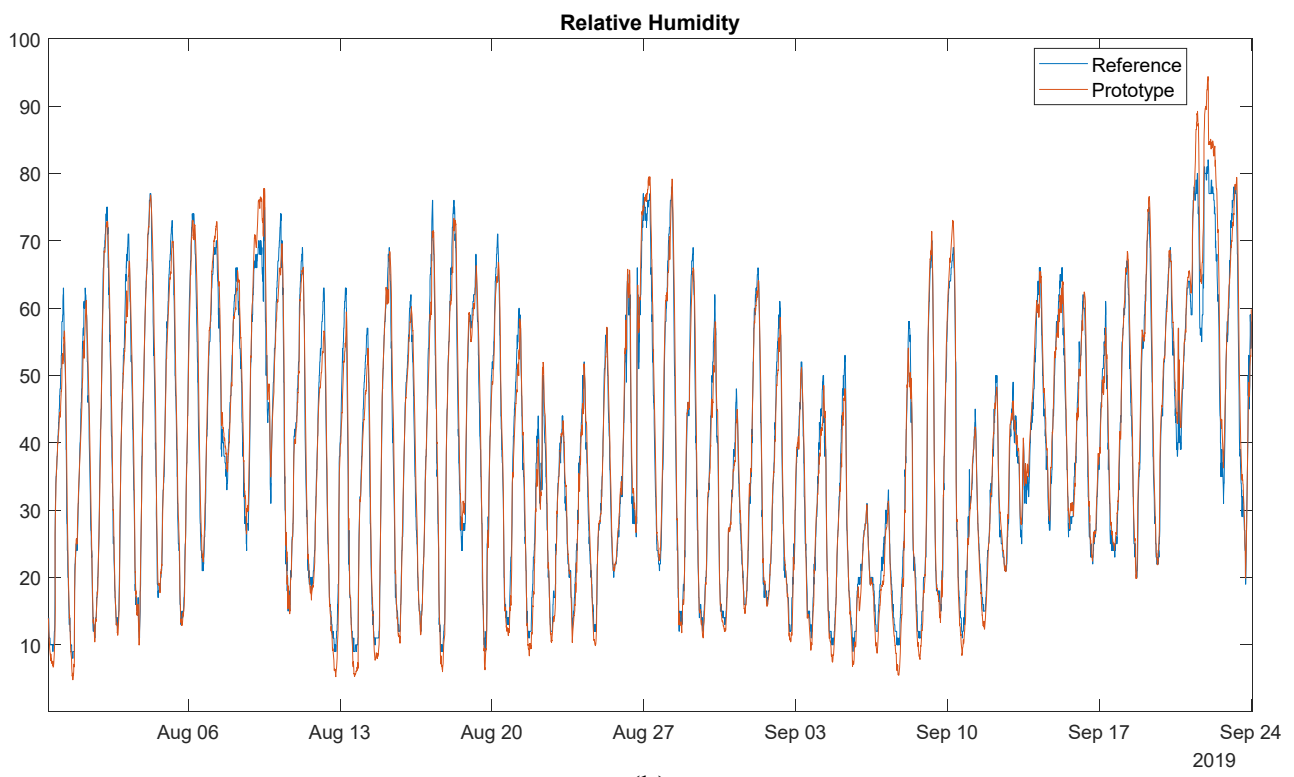

(b)

Figure 6: Meteorological data comparison chart. Blue: reference; Orange: prototype. (a) Temperature; and (b) Relative humidity. 


\subsection{Gas pollutants results}

Subsequently, an analysis of the correlation with the main polluting gases: $\mathrm{NO}_{2}, \mathrm{CO}$ and $\mathrm{O}_{3}$ has been carried out. In order to perform this study, it was first necessary to translate the units from ppb to $\mu \mathrm{g} / \mathrm{m}^{3}$ using eqn (1), where $\mathrm{M}=$ molecular weight; $\mathrm{R}=0.082$; atm $=$ pressure.

$$
{\frac{\mu g^{3}}{m}}^{3}=\frac{(p p b) *(a t m) *(M)}{\left(273.15+{ }^{\circ} \mathrm{C}\right) * R} .
$$

Once all data are compiled in the same unit and time scale (10 minutes), they are plotted as shown in Fig. $7\left(\mathrm{O}_{3}\right)$, Fig. $8(\mathrm{CO})$ and Fig. $9\left(\mathrm{NO}_{2}\right)$. As can be observed, the operation of the ozone sensor seems to be correct, as the signal follows the reference signal quite closely, although its performance could be improved with more accurate temperature and humidity compensation methods. Nevertheless, in the case of $\mathrm{NO}_{2}$ and $\mathrm{CO}$, the results are less accurate. This can be caused by the fact that the concentration of these pollutants in Badajoz is very low and, therefore, the effects of temperature and humidity variation are more noticeable.

\subsection{Particulate matter results}

Finally, the results obtained in $\mathrm{PM}_{10}$ and $\mathrm{PM}_{2.5}$ have been correlated. Both cases are represented in Fig. 10 and Fig. 11 respectively.

For these data corresponding to the PM concentration, no processing or correction of the previous data has been done, but the data coming directly from the sensor (OPC-N3) in $\mu \mathrm{g} / \mathrm{m}^{3}$ has been used.

It can be observed in this case that the concentration values provided by the prototype are lower than those of the reference station in a small range, but, nevertheless, the trend is followed correctly.

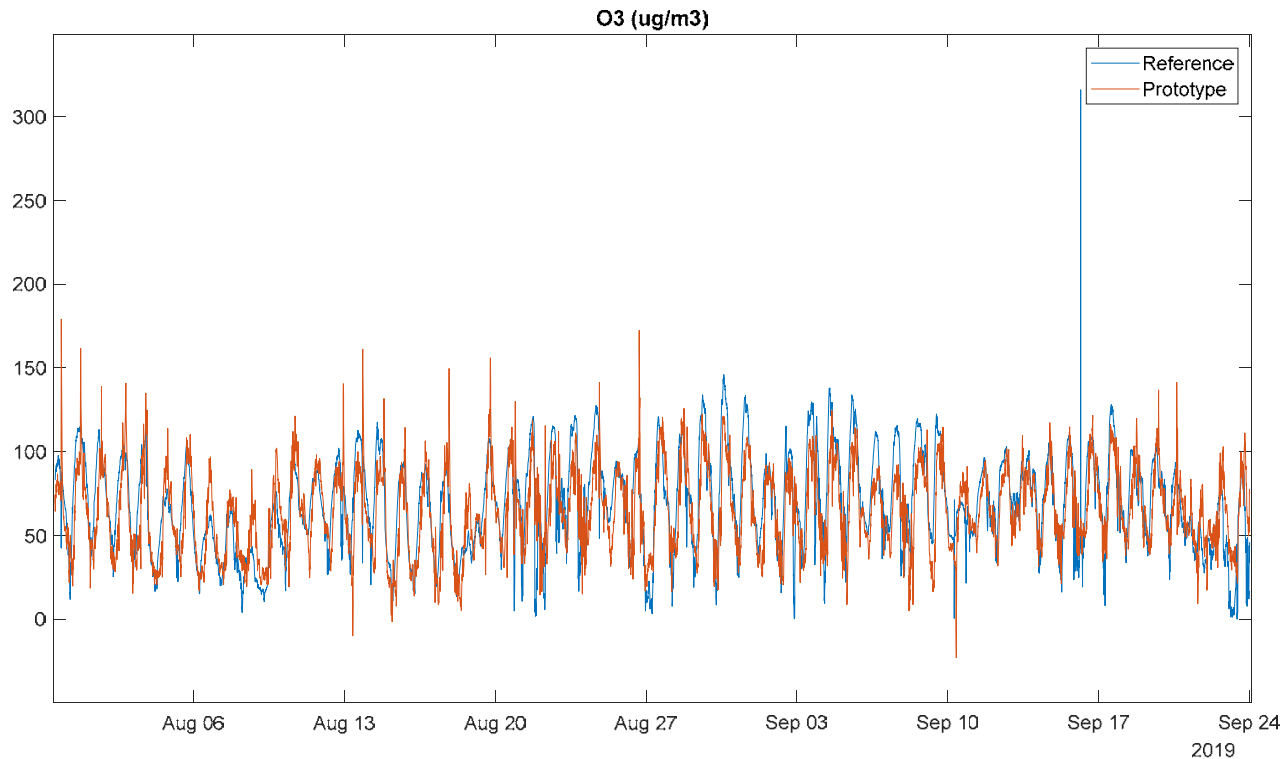

Figure 7: $\mathrm{O}_{3}$ comparison chart. Blue: reference; Orange: prototype. 


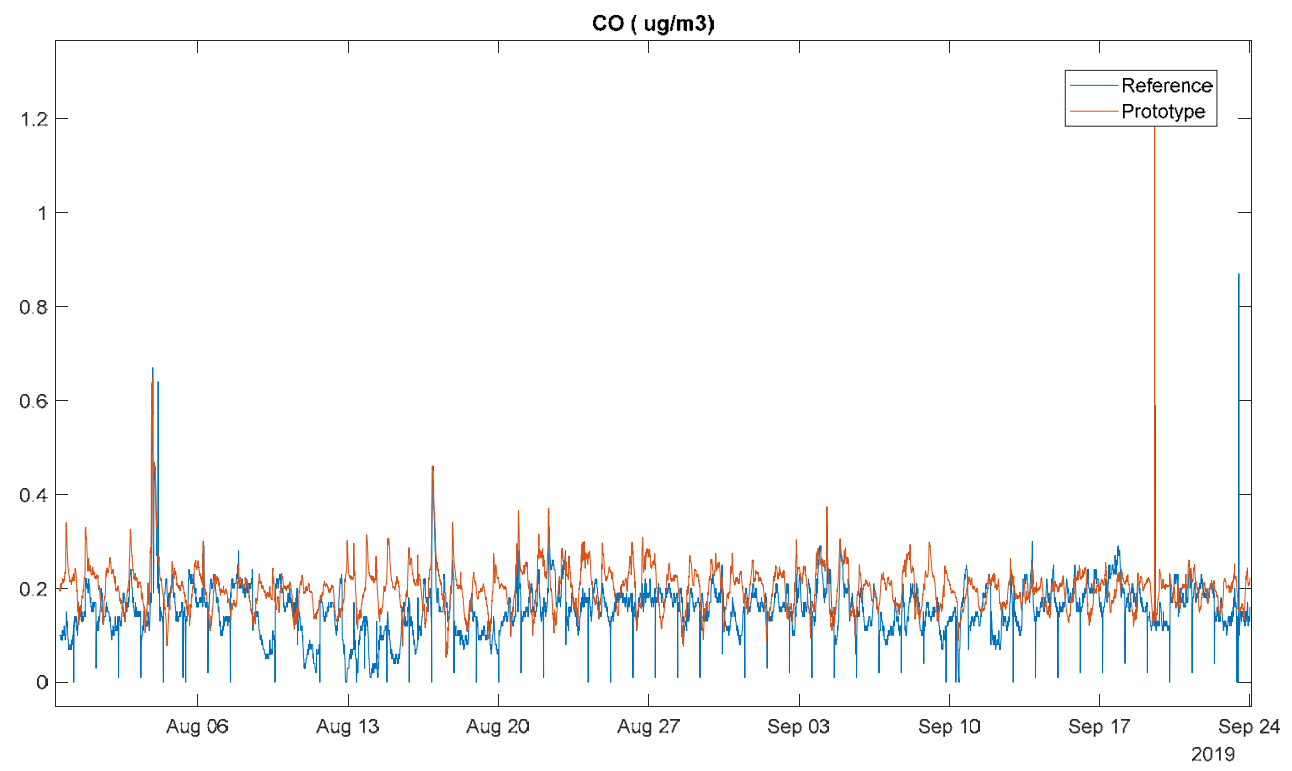

Figure 8: CO comparison chart. Blue: reference; Orange: prototype.

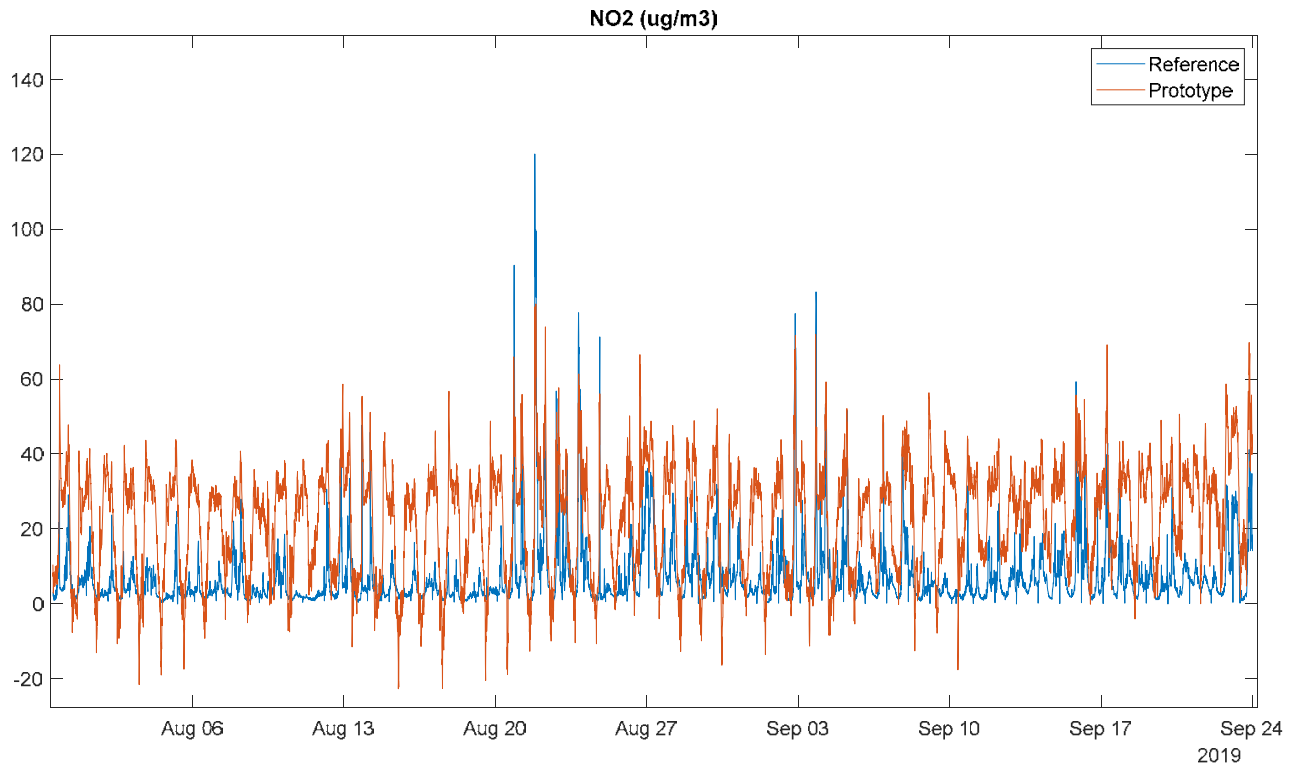

Figure 9: $\mathrm{NO}_{2}$ comparison chart. Blue: reference; Orange: prototype. 


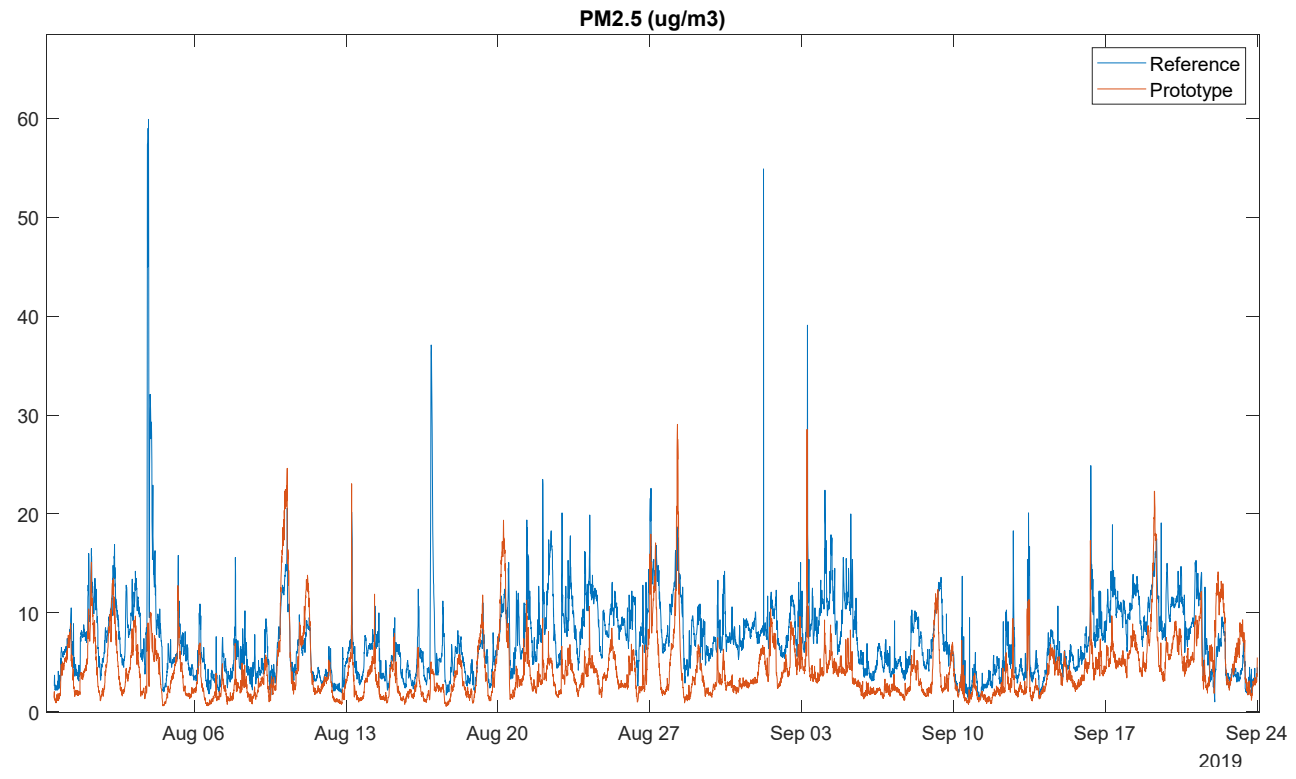

Figure 10: $\mathrm{PM}_{2.5}$ comparison chart. Blue: reference; Orange: prototype.

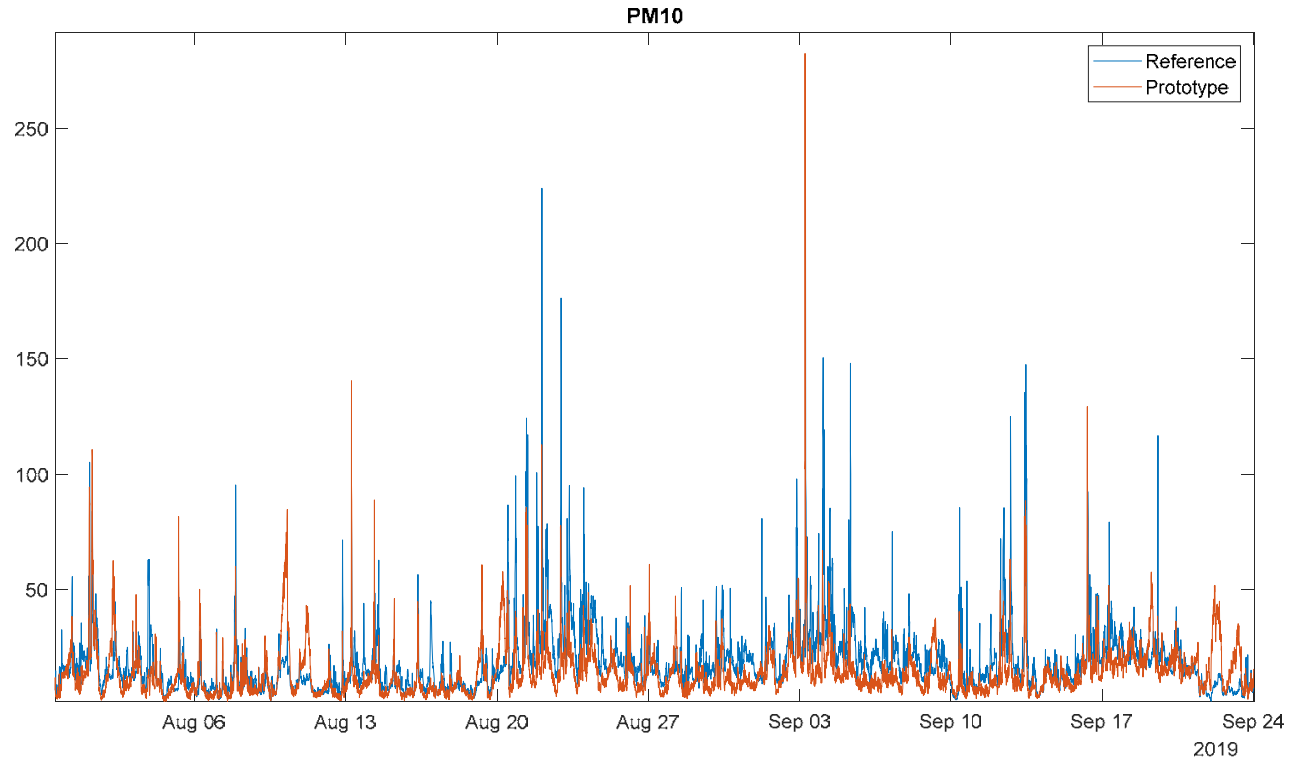

Figure 11: $\mathrm{PM}_{10}$ comparison chart. Blue: reference; Orange: prototype. 


\subsection{Application of artificial intelligence techniques}

In order to improve the results shown above, a preliminary test using artificial intelligence techniques has been carried out. Specifically, regression techniques have been used, in which the objective is to predict a set of properties (concentration) of a variable. For this purpose, the support vector regression (SVR) technique has been selected as it is generally the most used and recommended in gas sensor applications in the latest literature [9]-[11]. It consists of the use of support vector machine (SVM) in regression tasks [12]. This is achieved by minimizing the error condition through the so-called "linear $\varepsilon$-insensitive loss function". In addition, the representation by means of Kernel functions offers a non-linear problem solution, projecting the information to a space of characteristics of greater dimension which increases the computational capacity of the linear learning machines.

A Matlab toolbox (Statistics and Machine Learning Toolbox ${ }^{\mathrm{TM}}$ ) has been used for this purpose. In the implementation of SVM, the Kernel function used is a Gaussian function. The predictors used for the training were: the resulting signal in $\mu \mathrm{g} / \mathrm{m}^{3}$, the relative humidity value, and the temperature value in ${ }^{\circ} \mathrm{C}$.

Table 2 shows some of the main statistical indices of regression performance such as root mean square error (RMSE), coefficient of determination (R-squared), mean squared error (MSE) and the mean absolute error (MAE).

Table 2: Statistical indices.

\begin{tabular}{|l|c|c|c|c|}
\hline & RMSE & R-Squared & MSE & MAE \\
\hline $\mathrm{NO}_{2}$ & 6.3900 & 0.46 & 40.8320 & 3.1233 \\
\hline $\mathrm{O}_{3}$ & 13.946 & 0.76 & 194.48 & 9.2854 \\
\hline $\mathrm{NO}$ & 1.4025 & 0.10 & 1.9669 & 0.3218 \\
\hline $\mathrm{CO}$ & 0.0414 & 0.45 & 0.0017 & 0.0258 \\
\hline $\mathrm{PM}_{10}$ & 10.1660 & 0.48 & 103.36 & 4.8590 \\
\hline $\mathrm{PM}_{2.5}$ & 2.6692 & 0.57 & 7.1249 & 1.3334 \\
\hline
\end{tabular}

Fig. 12 shows the result obtained in the case of $\mathrm{CO}$ measurements. It reveals a significant improvement with respect to the original measurements (Fig. 8).

\section{CONCLUSIONS}

A portable and low-cost system has been designed for the measurement of the main air pollutants from electrochemical and PM sensors. This device has been installed for 2 months near a reference station to study its operation. The system has worked correctly during this campaign, with good results in correlation of humidity and temperature. Therefore, the electronics and design of the device is suitable for the measurement of contamination under real conditions.

On the other hand, contamination measurement results can be improved, especially in the case of low concentration pollutants (as is the case of $\mathrm{NO}_{2}$ and $\mathrm{CO}$ in Badajoz) by creating and improving calibration methods. This will also require new, longer measurement campaigns in places with higher levels of contamination. These will be the object of future work. 


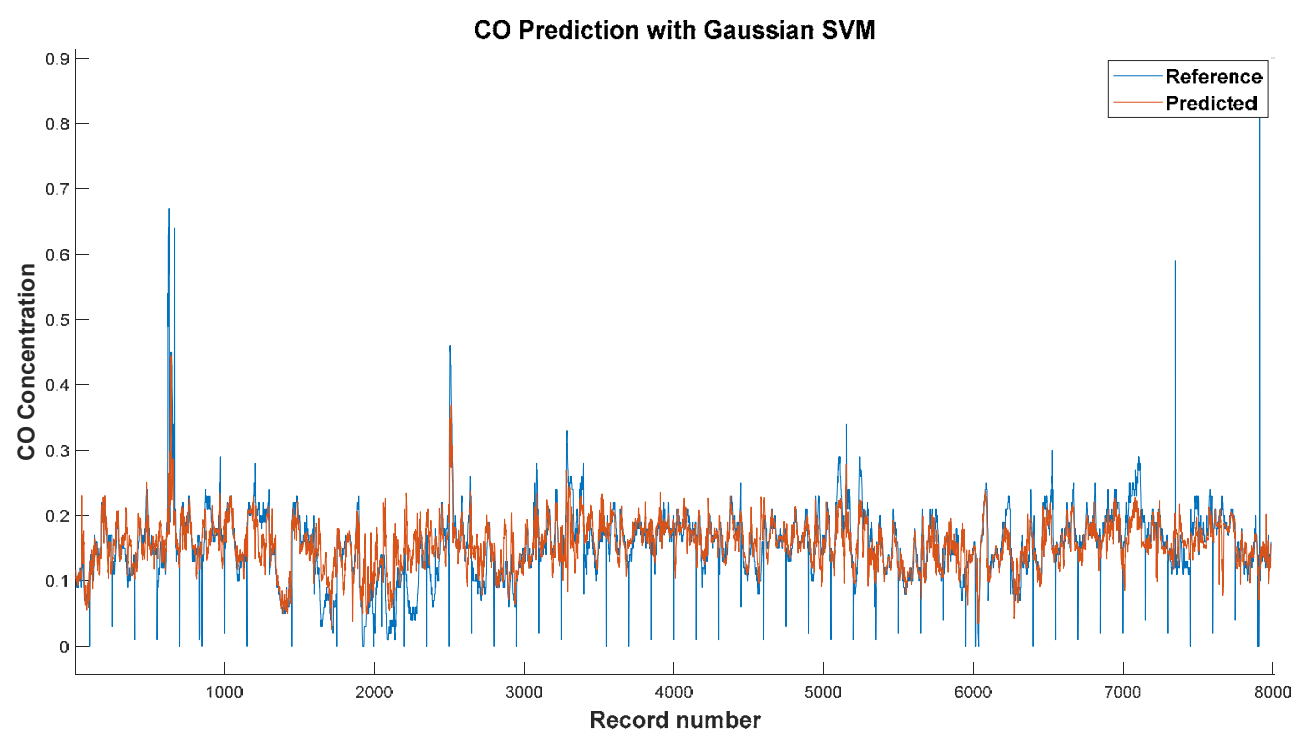

Figure 12: CO prediction chart using SVM techniques. Blue: reference; Orange: prototype (predicted).

\section{ACKNOWLEDGEMENTS}

The authors would like to thank the European Union for supporting NanoSen-AQM (SOE/P1/E0569), and Junta de Extremadura and FEDER (Fondo Europeo de Desarrollo Regional "Una manera de hacer Europa") for supporting the IB16048 project and GR18135.

\section{REFERENCES}

[1] McKercher, G.R., Salmond, J.A. \& Vanos, J.K., Characteristics and applications of small, portable gaseous air pollution monitors. Environmental Pollution, 223, pp. 102$110,2017$.

[2] Lung, C. et al., Low-Cost Sensors for the Measurement of Atmospheric Composition: Overview of Topic and Future Applications, World Meteorological Organization: Geneva, 2018.

[3] Aleixandre, M. \& Gerboles, M., Review of small commercial sensors for indicative monitoring of ambient gas. Chemical Engineering Transactions, 30, pp. 169-174, 2012.

[4] Cross, E.S. et al., Use of electrochemical sensors for measurement of air pollution: Correcting interference response and validating measurements. Atmospheric Measurement Techniques, 10(9), pp. 3575-3588, 2017.

[5] Jerrett, M. et al., Validating novel air pollution sensors to improve exposure estimates for epidemiological analyses and citizen science. Environmental Research, 158, pp. 286-294, 2017.

[6] DeSouza, P. et al., Nairobi experiment in using low cost air quality monitors: Background to the Nairobi case study. Clean Air Journal, 27(2), pp. 12-42, 2017.

[7] D'Alvia, L., Palermo, E. \& Del Prete, Z., Validation and application of a novel solution for environmental monitoring: A three month study at "Minerva Medica" archaeological site in Rome. Measurement, 129, pp. 31-36, 2018. 
[8] Lewis, A.C. et al., Evaluating the performance of low cost chemical sensors for air pollution research. Faraday Discussions, 189, pp. 85-103, 2016.

[9] De Vito, S. et al., Calibrating chemical multisensory devices for real world applications: An in-depth comparison of quantitative machine learning approaches. Sensors and Actuators B: Chemical, 255, pp. 1191-1210, 2018.

[10] Laref, R. et al., Support vector machine regression for calibration transfer between electronic noses dedicated to air pollution monitoring. Sensors, 18(11), p. 3716, 2018.

[11] Esposito, E., De Vito, S., Salvato, M., Fattoruso, G. \& Di Francia, G., Computational intelligence for smart air quality monitors calibration elena. Proceedings of ICCSA 2017: 17th International Conference, Trieste, Italy, July 3-6, pp. 443-454, 2017.

[12] Vapnik, V. \& Golowich, S.E., Support vector method for function approximation, regression estimation, and signal processing. Advances in Neural Information Processing Systems, 9, pp. 281-287, 1996. 